\title{
Application of geographic information system technique and analytical hierarchy process model for land-use suitability analysis on coastal area.
}

\begin{abstract}
Land-use suitability is the ability of a given type of land to support a defined use. GIS is known as a powerful tool for handling spatial data in land-use analysis. Application of this tool alone cannot overcome the lack of consistency in opinions given by experts when trying to assign relative importance to each of the several criteria considered in a suitability analysis. The combination of GIS and Multi-Criteria Decision Analysis (MCDA) is a powerful approach used to assess land suitability. To address this issue, the Analytical Hierarchy Process method is used in combination with the GIS tool. The aim of this study is to demonstrate how GIS tools and AHP model can be used for integrated coastal resource planning and management. Based on the information from final map/suitability map, we can define the best area. The findings indicate that the area $1(2111 \mathrm{~m})$ from class 3 is the most appropriate one because it has good facilities and wide open areas. This study indicates how the integrated tool is handled effectively in a land use suitability analysis for building hotels in the coastal areas of Terengganu in Malaysia. This research develops a framework for integrating GIS and AHP to incorporate the decision maker's preferences on a range of factors in finding land areas suitable for coastal development.
\end{abstract}

Keyword: GIS; AHP; Land-use suitability; Coastal management. 